\title{
Petogodišnji rezultati rada angiosale opšte bolnice Valjevo
}

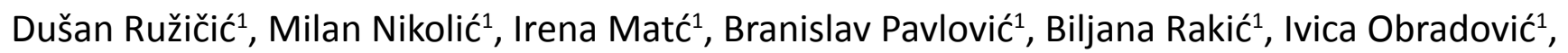 \\ Marko Stanković ${ }^{1}$, Slavica Vulović ${ }^{1}$, Vladimir Đorđevićc ${ }^{1}$, Danijel Cvetanovićc ${ }^{1}$, Milijana Terzić ${ }^{1}$, \\ Milan A Nedeljeković
}

${ }^{1}$ Sala za kateterizaciju srca, Opšta bolnica Valjevo, Valjevo

${ }^{2}$ Klinika za kardiologiju, Klinički centar Srbije, Beograd

Sažetak Uvod: Decenijama unazad, uprkos sve savremenijim metodama lečenja, ishemijska bolest srca zauzima neslavno prvo mesto kao uzrocnik mortaliteta u svetu. Preko sedam miliona ljudi širom sveta umire godišnje od koronarne bolesti. Trećina pacijenata koji dožive akutni infarkt miokarda sa ST elevacijom (STEMI) umire tokom prva $24 \mathrm{~h}$ od nastanka ishemije, a mnogi preživeli će iskusiti tešku formu bolesti sa komplikacijama i trajnu invalidnost. Dodatnih 5 do $10 \%$ pacijenata umire tokom prve godine nakon akutnog infarkta miokarda. Polovina pacijenata obolelih od AIM biva ponovo hospitalizovana tokom prve godine od početka bolesti.

Materijal i Metodi: Retrospektivno su analizirani angiografski nalazi pacijenata kojima je rađena invazivna dijagnostika i lečenje akutnih i hroničnih formi koronarne bolesti u Sali za kateterizaciju Opšte bolnice Valjevo od 21.12.2010 do 15.09.2015 godine. Podaci su prikupljeni iz registra bolesnika Sale za kateterizaciju OB Valjevo, a analizirani su metodama deskriptivne statistike. Dobijeni rezultati prikazani su grafički i tabelarno.

Rezultati: Od 21.12.2010. godine do 15.09.2015. u Opštoj bolnici Valjevo, 880 pacijenata ili $99 \%$ od ukupnog broja primljenih STEMI primenjena je mehanicka revaskularizacija miokarda metodom primarne perkutane koronarne intervencije ( $\mathrm{pPCl})$. Prosečno, mesecno je 18.1 STEMI pacijent lečen metodom pPCl, a godišnje 193.2 pacijenta. Kod 186 pacijenta sa akutnim infarktom miokarda bez ST elevacije (NSTEMI) rađena je PCI prema preporukama unutar 48 do $72 \mathrm{~h}$, a 831 pacijenat je zbrinuto elektivnom PCl. Ukupno je učinjeno 4671 koronarografija, 1619 procedura invazivne dijagnostike na perifernim krvnim sudovima sa 310 perkutanih angioplastika na perifernim krvnim sudovima. Kod 217 bolesnika sa teškim srčanim aritmijama ugradjen je stalni antibradikardni pejsmejker.

Zaključak: Uvođenjem metoda primarne perkutane koronarne intervencije (pPCI) mortalitet pacijenata sa STEMI je sveden na oko 6-7 \%. Trenutak i brzina otvaranja zapušene koronarne arterije u STEMI podjednako su važni kao i način revaskularizacije radi održavanja protoka, očuvanja miokarda i preveniranja komplikacija.

Ključne reči akutni infarkt miokarda sa ST elevacijom, koronarografija, angiosala OB Valjevo.

\section{Uvod}

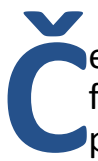
etvorogodišnjim praćenjem pacijenata sa stabilnom formom koronarne aterosklerotske bolesti-anginom pektoris (AP), prema podacima REACH registra, pokazano je da će veliki procenat, gotovo polovina (45\%), iskustiti novi veliki neželjeni kardiovaskularni događaj (smrt, akutni infarkt, cerebrovaskularni insult, rehospitalizaciju) ${ }^{1}$. Zbog maligne prirode i toka koronarne bolesti, imperativ je bio iznalaženje efikasnijih metoda lečenja.

Prema najnovijim preporukama Evropskog i Americ- kog udruzenja kardiologa (ESC i AHA/ACC) primarna perkutana intervencija ( $\mathrm{pPCl}$ ) je superiorna u odnosu na farmakološku trombolizu u akutnom infarktu miokarda sa ST elevacijom (STEMI) ukoliko se uradi pravovremeno, 12 sati od početka simptoma, a primenljiva je i kod pacijenata sa simptomima infarkta (STEMI) unutar 24 sata od pocetka bolestiti,2,3,4,5.

Zahvaljujući brojnim dokazima o drastičnom smanjenju mortaliteta, mehanička reperfuzija postala je dominantna strategija lečenja akutnog infarkta miokarda sa ST elevacijom u većini evropskih zemalja danas ${ }^{9,10,11}$. Sve navedeno predstavljalo je veliki podsticaj za dalje širenje 
mreže angiosala u svetu i u Srbiji, kao i formiranje ekipa obučenih eksperata sposobnih za lečenje kompeksnih, hroničnih i akutnih formi koronarne bolesti.

\section{Metodi i rezultati}

Od svog otvaranja 21. decembra 2010. godine angiosala Opšte bolnice Valjevo zbrinjavala je sve pacijente Kolubarskog i deo pacijenata Mačvanskog okruga, obolele od akutnog infarkta miokarda sa i bez ST elevacije upućene na hitnu revaskularizaciju miokarda metodom primarne $\mathrm{PCl}$ ili rescue $\mathrm{PCl}$.

Tabela 1. Udaljenost regionalnig zdravstvenih ustanova od Sale za kateterizaciju Bolnice Valjevo i vreme potrebno za transport pacijenata sa STEMI

\begin{tabular}{|l|r|r|r|}
\hline Grad & Br stanovnika & $\begin{array}{l}\text { Udaljenost od } \\
\text { Sale /u km/ }\end{array}$ & $\begin{array}{l}\text { Vreme } \\
\text { Putovanja / } \\
\text { min/ }\end{array}$ \\
\hline Valjevo & & & \\
\hline Osecina & 15135 & 34.81 & 40 \\
\hline UB & 32104 & 29.17 & 20 \\
\hline Lajkovac & 17062 & 27.61 & 15 \\
\hline Mionica & 16513 & 19.61 & 10 \\
\hline Ljig & 14629 & 38.12 & 35 \\
\hline Sabac & 1229893 & 70.0 & 40 \\
\hline Loznica & 86413 & 75.54 & 70 \\
\hline Koceljeva & 15636 & 30.6 & 20 \\
\hline Mali Zvornik & 14076 & 111.44 & 120 \\
\hline Krupanj & 20192 & 66.07 & 50 \\
\hline Ljubovija & 17000 & 67.74 & 90 \\
\hline Bogatić & 32.990 & 91.45 & 50 \\
\hline Valdimirci & 20.373 & 53.12 & 30 \\
\hline
\end{tabular}

Prema podacima iz 2002 godine, ovo područje obuhvata ukupno 540.204 stanovnika, koji su raspoređeni u više opština maximalne udaljenosti $111.44 \mathrm{~km}$ od Sale za kateterizaciju naše bolnice, do koje stižu za najviše 120 min saintetskim vozilom (Tabela 1).Zahvaljujući odličnoj koordinaciji između naše ustanove i Regionalnih bolnica spomenutih gradova kao i Domova zdravlja i dobro organizovanoj, neprekidnoj, 24h 7 dana u nedelji pripravnosti ekipe interventnih kardiologa Opšte bolnice Valjevo, za 4 godine 9 meseci i 15 dana urađeno je 880 primarnih perkutanih koronarnih intervencija u akutnom inafrktu miokarda sa ST elevacijom.U ovom periodu u Koronarnu jedinicu naše bolnice je primljeno 890 pacijenta sa dijagnozom STEMI, što znači da je $99 \%$ zbrinuto mehaničkom revaskularizacijom miokarda.Od ukupnog broja lečenih infarkta sa ST elevacijom 616 pacijenata su bili iz Kolubarskog Okruga (filijala Valjevo Republičkog Fonda za zdravstveno osiguranje) , a 264 pacijenta stranih zavoda (ostalih filijala u navedenim okruzima).

Kod 794 STEMI pacijenata procedura $\mathrm{pPCl}$ je završena implantacijom stenta, a kod 58 pacijenata urađena je samo balon dilatacija (POBA). Kod četiri obolela primenjena je samo aspiracija trombne mase iz lumena infarktne arterije i procedura je na taj način završena, jer je dobijen adekvatan koronarni protok TIMI 3 bez značajne rezidualne ste- noze. Četrnaest bolesnika upućeno je na hitnu hiruršku revaskularizaciju miokarda (CABG) u tercijarnu kardiohiruršku ustanovu i uspešno su operisani (Grafikon 1). Devet pacijenata sa kliničkom slikom STEMI je imalo normalan angiografski nalaz tokom hitno učinjene koronarografije.

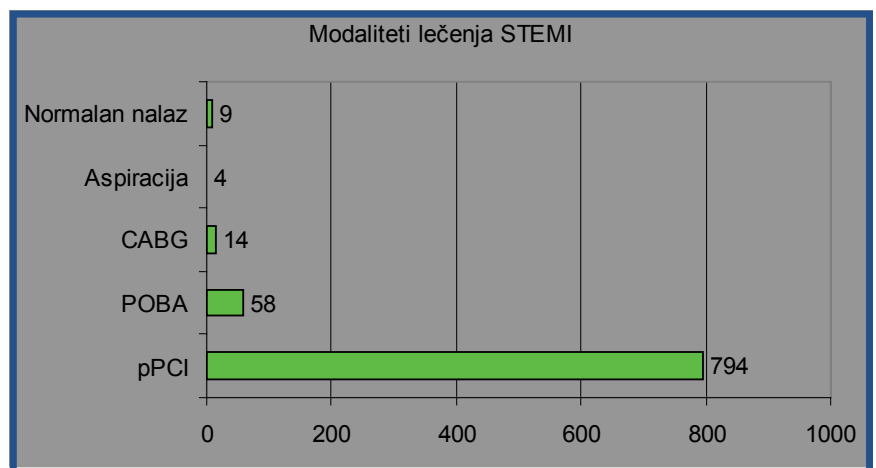

Slika 1. Modaliteti lečenja STEMI

Procenat uspešnosti primarnih perukatnih koronarnih intervencija je visok i iznosi oko 98\%, naime samo kod 18 pacijenata (2\%) zbog prirode lezije i/ili nedostakta adekvatnog materijala, nije bilo moguće plasirati koronarnu žicu u distalni segment infarktne arterije.(Grafikon 2).

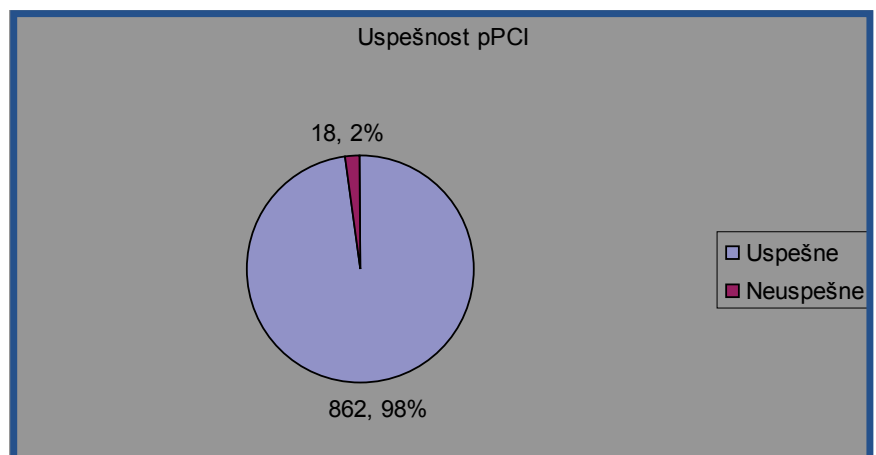

Slika 2. Procenat uspešnih pPCI

Od 880 pacijenata sa dijagnozom akutnog infarkta miokarda sa ST elevacijom, $1.59 \%$ ili ukupno 14 pacijent je upućen na hitnu CABG , nakon samo dijagnostičke koronarografije. Jedanaest bolesnika je prvo zbrinuto u angiosali otvaranjem infarktne arterije metodom primarne perkutane koronarne intervencije sa implantacijom stenta ili je ucinjena POBA, a potom upućeni na CABG. Prosečno mesečno je zbrinjavano 18.1 pacijenta sa STEMI a godišnje 193.2 (Grafikon 3).

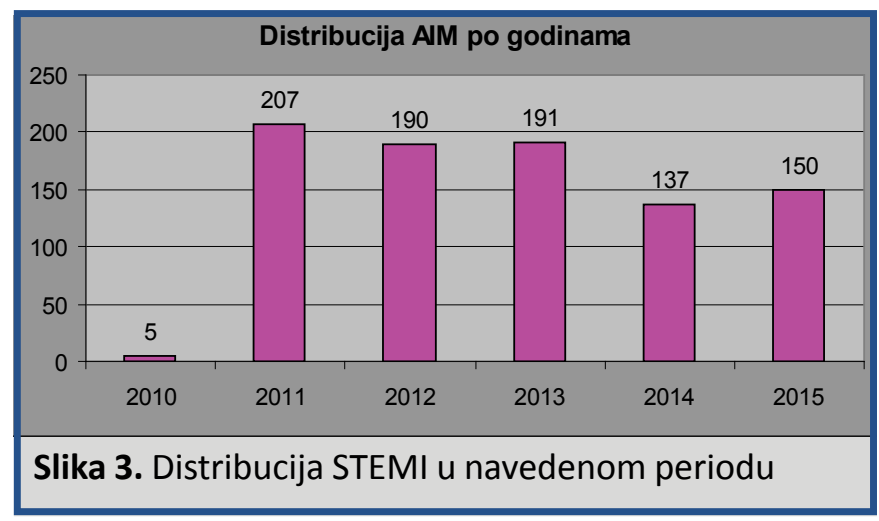


karda uoćava se da je najviše novih slučajeva akutnog infarkta miokarda sa ST elevacijom u letnjim i zimskim mesecima (Grafikon 4).

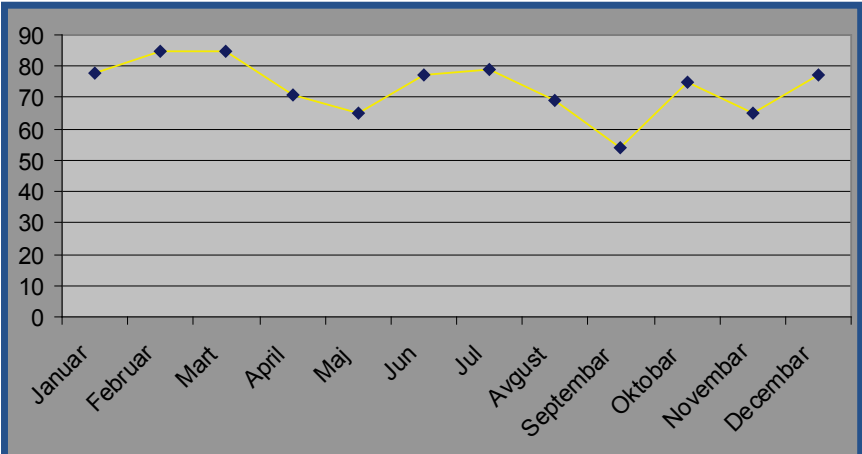

Slika 4. Distribucija AIM po mesecima

Broj infarktnih arterija na kojima je rađena perkutana intervencija (POBA, implantacija stenta, aspiracija tromba) je 880, kod još 10 pacijenta sa kardiogenim šokom rađena je $\mathrm{u}$ istom aktu i kompletna revaskularizacija. Kuplrit lezija je u najvećem broju slučajeva na prednjoj descendentnoj arteriji (LAD), potom na desnoj koronarnoj arteriji (RCA), zatim na cirkumfleksnoj koronarnoj arteriji (Cx) i manji broj na glavnom stablu (LM), dijagonalnoj grani (DG) i venskom graftu (Grafikon 5).

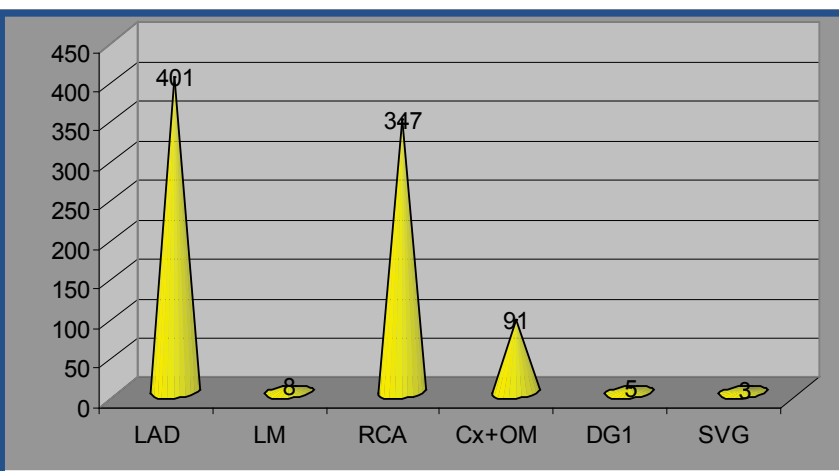

Slika 5. Lokalizacija culprit lezije

Periproceduralni mortalitet obolelih sa STEMI koji su zbrinjavani u našoj angiosali metodama primarne perkutane koronarne intervencije je iznosio oko $2 \%$ ( 18 pacijenata od 880 je umrlo) (Grafikon 6).

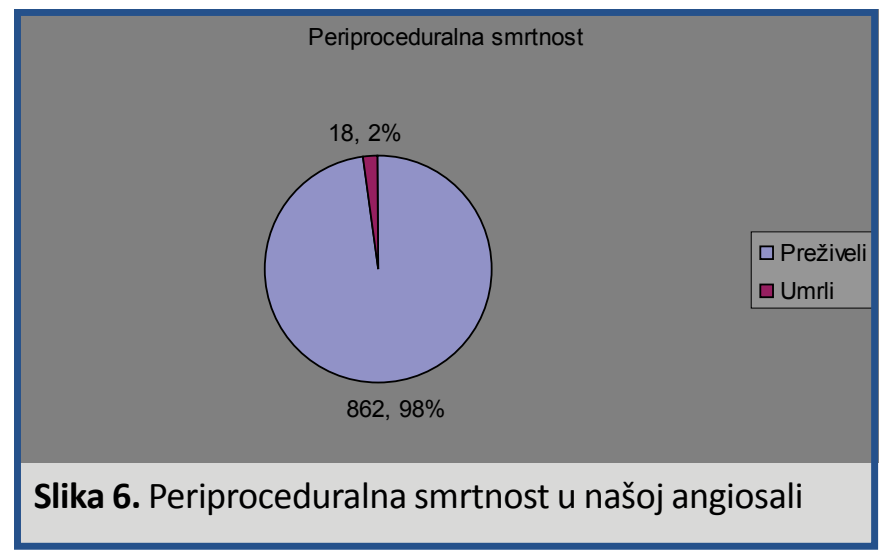

Do 15.septembra 2015 godine, 4671 pacijenta je koronarografisano, učinjeno je ukupno 1897 perkutanih koronarnih intervencija, gotovo polovina od njih u akutnom infarktu sa ST elevacijom. Kod 186 pacijenta sa akutnim infarktom miokarda bez ST elevacije (NSTEMI) radjena je perkutana koronarna intervencija prema preporukama unutar 48 do $72 \mathrm{~h}$. Broj uradjenih elektivnih procedura (831) bio je uslovljen između ostalog i ograničenom količinom materijala koji se godišnje opredeljuje od strane RFZO-a, realno bi trebao biti veci (Garfikon 7, 8).

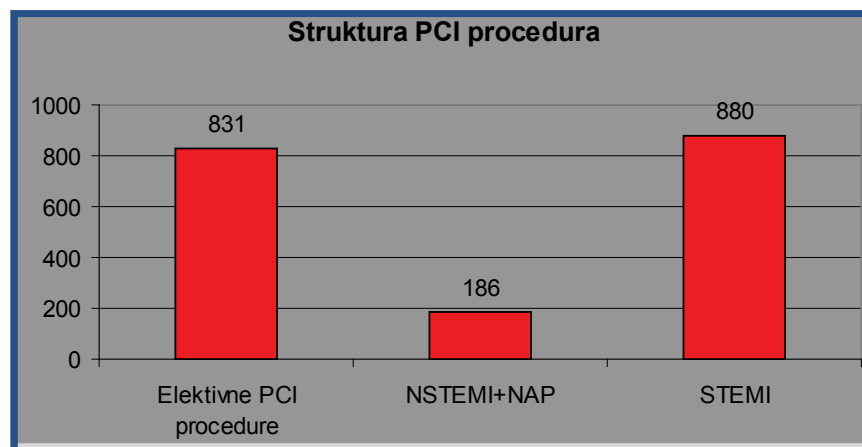

Slika 7. Struktura $\mathrm{PCI}$ procedura u angiosali OB Valjevo u posmatranom periodu

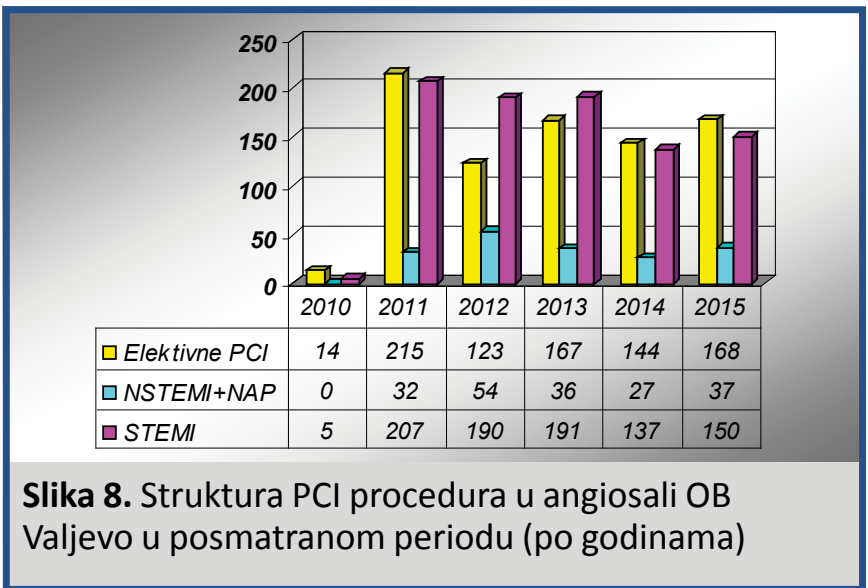

Kako je Sala za kateterizaciju Opšte bolnice Valjevo projektovana za invazivnu dijagnostiku i zbrinjavanje drugih vidova perifernih vaskularnih bolesti, od samog početka njenog rada do 15 septembra 2015. godine učinjeno je i 1309 angiografija i 310 perkutanih angioplastika na perifernim krvnim sudovima. Kod 217 bolesnika sa teškim srčanim aritmijama ugrađen je stalni antibradikardni pejsmejker ili ICD defibrilator.

\section{Diskusija}

U SAD se dijagnostikuje 1.500 .000 novih slučajeva akutnog infarkta miokarda godišnje, sa incidencom od 600 novih slučajeva na 100.000 stanovnika. 500-700.000 ljudi umire godišnje od koronarne bolesti ${ }^{5}$. Prema podacima iz Registra za akutni koronarni sindrom 2010.godine, vodeći uzrok umiranja u Srbiji su bolesti srca i krvotoka 54.7\%, a polovina ovih pacijenata umire od akutnog koronarnog sindroma. Standardizovana stopa incidence akutnog infarkta miokarda sa ST elevacijom na 100.000 stanovnika za Mačvanski i Kolubarski okrug 2010. godine 
je ista 110.1 do 130.1 . Standardizovana stopa mortaliteta od akutnog inafrkta miokarda na 100.000 stanovnika u Srbiji 2010. godine je za Mačvanski okrug 40.1 do 50.0, a za Kolubarski okrug ispod 30.02,4. Davne 1993. godine prva randomizovana studija pokazala je da je primarna perkutana intervencija superiorna $u$ odnosu na trombolizu u akutnom infarktu miokarda sa ST elevacijom ${ }^{5,9,10,12,13,14}$. Najnovije preporuke za izvođenje primarnih perkutanih koronarnih intervencija su formulisane u saradnji sa radnom grupom EAPCl, Evropskog udruženja kardiologa. Primarna $\mathrm{PCl}$ je indkovana (klasa I) kod pacijenata sa ishemijskih simptomima koji su započeli pre manje od $12 \mathrm{~h}$, kod onih sa ishemijskim simptomima ispod $12 \mathrm{~h}$ trajanja i kontraindikacijama za fibrinolitičku terapiju i kod pacijenata sa kardiogenim šokom ili akutnom teškom srčanom insuficijencijom (bez obzira na odložen dolazak u Salu za katetrizaciju). Primarnu PCI je razumno primeniti (klasa lla) kod nestabilnih pacijenata sa perzistentnim simptomima unutar $24 \mathrm{~h}$ od nastanka infarkta. Prema rezultatima OAT studije, odloženu $\mathrm{PCl}$ ne treba primenjivati kod totalno okludirane infarktne arterije nakon više od $24 \mathrm{~h}$ od početka akutnog infarkta miokarda sa ST elevacijom, ukoliko su pacijenti stabilni i asimptomatični. U vreme pPCI ne treba izvoditi proceduru na ne-infarktnoj arteriji (klasa III) ukoliko pacijent nije hemodinsmki kompromitovan ${ }^{3,4}$.

Otvaranjem Sale za kateterizaciju u Regionalnoj opštoj bolnici Valjevo, pola miliona stanovnika Mačvanskog i Kolubarskog okruga je dobilo mogućnost najsavremenijeg i najefikasnijeg lečenja akutnog koronarnog sindroma, a posebno infarkta miokarda sa ST elevacijom. Za nešto više od 4.5 godine rada 880 obolelih od akutnog infarkta miokarda sa ST elevacijom je zbrinuto mehaničkom reperfuzijom, sa velikom uspešnošću (98\%). Gotovo polovina pacijenata od ukupnog broja infarkta (401) imala je okluziju prednje descendentne arterije, koja ishranjuje veliko područje miokarda. Pravovremenim otvaranjem ove arterije sprečlava se evolucija velikog infarkta, nastanak malignih poremećaja ritma ili sprovođenja, srčane insuficijencije, kardiogenog šoka i drugih potencijalno smrtonosnih komplikacija. Broj neuspešnih procedura, odnosno nemogućnost da se uspostavi TIMI 3 protok kroz infarktnu arteriju je 18. Daljim razvojem tehničke podrške i saradnje sa regionalnim centrima, postićiće se da pacijent brze stigne do angiosale iz bilo kog grada oba okruga, a samim tim i povecati efikasnost samih procedura.

Stvranjaem mreža angiosala u Srbiji, povećala se dostupnost različitih invazivnih dijagnostičkih i terapijskih metoda interventne kardiologije, za koje postoje ogromne liste čekanja u svim velikim centrima tercijarnog nivoa zdravstvene zaštite. Na dijagnostičku koronarografiju pacijenti iz unutrašnjosti su obično čekali više meseci, a reperfuzija metodom primarne $\mathrm{PCl}$ je bila rezervisana samo za sporadične slučajeve. Od pocetka rada angiosale OB Valjevo, učinjeno je ukupno 4671 koronarografija i 1897 procedure perkutane koronarne intervencije, od toga 831 elektivna $\mathrm{PCl}$. Implantirano je 217 stalnih antibradikardnih pejsmekera ili ICD defirbilatora i 1309 procedura invazivnog snimanja perifernih krvnih sudova kao i 310 perkutanih angioplastika perifernih krvnih sudova..

\section{Zaključak}

Otvaranjem Sale za kateterizaciju u Opštoj bolnici Valjevo omogućena je primena najsavremenijih metoda dijagnostike i lečenja koronarne bolesti, periferne arterijske bolesti i malignih aritmija. Odlukom da se od početka rada sprovodi program $24 \mathrm{~h} 7$ dana u nedelji zbrinjavanja akutnog infarkta miokarda sa ST elevacijom postignuto je značajno smanjenje mortaliteta ovih pacijenata kao i nastanak ranih i kasnih komplikacija, te smanjenje invaliditeta i povećanje radne sposobnosti obolelih sa područja Kolubarskog i Mačvanskog okruga.

\section{Literatura}

1. Deepak L. Bhatt, Kim A. Eagle, E. Magnus Ohman, et all. Comparative Determinants of 4-Year Cardiovascular Event Rates in Stable Outpatients at Risk of or With Atherothrombosis. JAMA.2010;304(12):1350-1357

2. Incidencija i mortalitet od akutnog koronarnog sindroma u Srbiji, 2010. Registar za akutni koronarni sindrom. Izveštaj br 5.Institut za javno zdravlje Srbije „dr Milan Jovanović Batut”

3. The Task Force on the management of ST-segment elevation acute myocardial infarction of the European Society of Cardiology (ESC).ESC Guidelines for the management of acute myocardial infarction in patients presenting with ST-segment elevation. Eur Heart J 2012;33: 2569-2619.

4. Ostojić $M, A$ šanin $M$, Vasiljević Pokrajčić Z, Peruničić J, Nedeljkovic M, Stanković G, Stojković S, Dobrić M. Akutni koronarni sindrom. Srce i krvni sudovi 2011;30(3):161-172.

5. Levine G. The 2013 STEMI Guideline: Data-driven Recommendations that Reduce Morbidity and Mortality.Cardiovascular Daily,2012; dec 18.

6. Jianping Li,Yong Huo. Personalised antiplatelet therapy: are we ready for prime time? Data from China. Eurolntervention 2013; 9:296-298.

7. Kesler M, Rottbauer W, Koenig W.Clinical assessment, platelet reactivity measurement or genetic testing after acute coronary syndrome? What benefits the patient?Eurolntervention 2013;9:299301.

8. W Z Mounir , L Basalus, Joner et all. Polymer coatings on drugeluting stents: Samson's hair and Achilles' heel? Eurolntervention 2013;9:302-305.

9. Otten AM, Maas AHM, Ottervanger JP, et al.Is the difference in outcome between men and women treated by primary percutaneous coronary intervention age dependent?: Gender difference in STEMI stratified on age. EHJ Acute Cardiovasc Care 2013.

10. Vakili BA, Kaplan RC and Brown DL. Sex-based differences in early mortality of patients undergoing primary angioplasty for first myocardial infarction. Circulation 2001; 104:3034-3038.

11. Singh M, Rihal CS, Gersh BJ, et al. Mortality between men and women after percutaneous coronary interventions: 25-year, single-center experience. J Am Coll Cardiol 2008; 51: 2313-2320.

12. Frink RJ. Gender gap, inflammation and acute coronary disease: are women resistant to atheroma growth? Observations at autopsy. J Invasive Cardiol 2009; 21: 270-277.

13. Shaw LJ, Bugiardini R and Bairey Merz CN. Women and ischemic heart disease. J Am Coll Cardiol 2009; 54: 1561-1575.

14. Di Chiara A, Chiarella F, Savonitto $S$ et al.Epidemiology of acute myocardial infarction in the Italian CCU network. The BLITZ Study. Eur Heart J 2013 ;24:1616-1629. 